\title{
SPHERICAL PANORAMAS, AND NON METRIC IMAGES FOR LONG RANGE SURVEY, THE SAN BARNABA SPIRE, SAGRADA FAMILIA, BARCELONA, SPAIN
}

\author{
Elisa CINGOLANI, Gabriele FANGI \\ Università Politecnica delle Marche - Ancona, Italy \\ elisacingolani1987@libero.it,g.fangi@univpm.it
}

Keywords: Spherical photogrammetry, long focal length, non-metric images

\begin{abstract}
The Sagrada Familia by Gaudi in Barcelona about 80 years after the death of its creator is going quickly to take its final shape as well as, maintain its original form as Gaudi would have wanted, the actual builders say. Complicated and elaborated forms, following the construction layout of the Chapel of Colonia Guell in Santa Coloma, tend to reproduce, on a gigantic scale, the organic forms of trees going to draw the charming and attractive complex of the small church derived from the model of wires used by Gaudi for its design. It has been long debated, and still it is debated on this approach as "camouflage", how it is consistent with the attitude of Gaudi architecture in the sense that he saw a sort of self-generating form of architecture during its own construction gradually responding to the stress placed by the same growth of structures, shapes, and materials. ("We do not reproduce the forms but we are able to reproduce a character owing its spirit," A. Gaudi). But beyond this, the reality remains of the gradual suppression of what Gaudi realized until his death. Basically the sole facade of the Nativity, with its striking features and ending with four original towers as hyperboloids pinnacles with glittering glazed mosaics, is the only one that was finished by Gaudi himself, in particular the San Barnaba's spire. In this action of progressive "destruction", it is very important to analyze, survey and plot what realized by Gaudi for recovering the original forms and keeping them in their Gaudian formal and constructive features. The spire of St. Barnabas is one of the most architecturally significant occurrence of the whole building and its survey poses major technical problems: their possible solution represented by the experience here shown, has been already experimented in the previous 90 years as one of the first applications of expeditious photogrammetric techniques of survey (Clini, Fangi,1990). The technical problems consist basically in the difficulty given by its height above the street level, about 100 meters. Long focal lenses have to be used to get a suitable resolution and accuracy. We wanted to repeat now the survey using a different photogrammetric technique from the old one, that was DLT algorithm for non-metric images. The new technique is the Spherical Photogrammetry. Multi-image Spherical Photogrammetry makes use as sensor of a pseudo-image that is the spherical panorama, composed by the images taken from the same station point. For details of Spherical Photogrammetry see (Fangi, 2,3,4,9). A particular procedure appropriate for the orientation of very narrow field of view lenses panorama has been already set up and used for the orientation and plotting of the three minarets of the Great Mosque of Omayyad's in Damascus, Syria. Their heights range from 60 to 80 meters above the courtyard pavement of the mosque. The technique consists in taking different focal lengths panorama from the same station point (Fangi, New Castle, 2010), one with WA wide angle and another one with NA Narrow Angle, adding to the stability of WA panorama the resolution of NA panorama. The same approach has been used in the Sagrada Familia, for the survey of San Barnaba's spire. In 1990 the A. made a survey of the same spire. But in comparison to the years 90, there is one difficulty more: now the rear of the spire is not visible because of the construction of the roof of the church, while it was visible in 1990. The solution has been then to use the original images taken in the years 90 for the rear of the spire and the spherical panoramas for the rest, i.e. the part toward the façade, using the original control points. Then we had to make a combined adjustment of non metric images using DLT approach and spherical photogrammetry algorithms. The restitution has been indeed carried out using both type of imagery, spherical panorama and non metric images. The results are satisfactory in the sense that the principles of quick photogrammetry have been respected: short surveying times, simple and inexpensive tools, reaching in any case suitable outcome.
\end{abstract}

\section{INTRODUCTION}

The Spherical Photogrammetry is a new photogrammetric technique making use not of the original photographic images but of a kind of cartographic projection (spherical panorama) of a virtual sphere where are projected the original images, taken from the same point at $360^{\circ}$ around. For the details of the technique see (Fangi, 2, 3, 4, 8, 9). From the panorama point coordinates the two directions to the corresponding object point are derived. The object space is then obtained by intersection of projective lines coming from two or more oriented panoramas. The successful examples of 
survey are already very many. The advantages are very high resolution, FOV up to $360^{\circ}$, completeness of documentation, possibility to make Quicktime movies, very short surveying times, low-cost equipment.

\section{THE PANORAMAS WITH NARROW FOV}

In the spherical panorama, the radius of the virtual sphere coincides with the focal length of the camera, or with its principal distance, where the distortions have been already estimated and corrected by the stitching software itself, by overlapping the images. The calibration, that is essentially the determination of the principal distance, takes place closing at $360^{\circ}$ the panorama. The closing error $\xi$ is distributed over all the images and the corrected principal distance $R^{\prime}$ is got from the original value of the radius $\mathrm{R}$ simply by: $R^{\prime}=R(360-\xi) / 360^{\circ}$ (Szeliski, 1997). In the case of narrow or very narrow FOV lens it becomes in practice impossible to close at $360^{\circ}$ the panorama because of the too many images needed. In this case it is preferable to couple the NA pano with one WA pano, taken from the same station point and carry out the selfcalibration with a block adjustment by imposing the geometrical constraint of the coincidence of the two taking points. The WA geometry is a robust one although the resolution is poor, while NA pano has a week geometry but a good resolution. This is already a good reason to couple WA panorama with NA ones; in addition this combination is necessary for another reason too.

\subsection{The set-up of the panorama}

In the panorama formation phase an essential operation for a good result of the survey, (accuracy of the restitution), is the vertical set-up of the sphere axis, corresponding to the set-up of the theodolite. The remaining lack of verticality can be estimated and corrected by two correction angles in the subsequent orientation phase, but their value should be as small as possible. In fact in our approach the model formation is performed by setting to zero initially the two corrections angles, which are afterwards estimated in the block adjustment. To get the vertical set-up, performed during the panorama formation inside the stitching software, at least two vertical lines in the object space should be observed, and they have to be placed possibly $90^{\circ}$ apart one from the other in the pano. In WA pano, this condition is easily satisfied while in the NA pano the imaged zone is normally a small part of the sphere: one can find a vertical line in this zone, in a meridian plane, setting to zero the rotation $\alpha_{\mathrm{x}}$ around the axis passing through it (figure 1) but hardly another one $90^{\circ}$ apart from this one, making impossible to set near to zero the other angle $\alpha_{\mathrm{y}}$. A correct $\alpha_{\mathrm{y}}$ estimation can be done using the WA panorama: in fact the two zenithal directions $\mathrm{Z}_{\mathrm{NA}}$ and $\mathrm{Z}_{\mathrm{WA}}$ (one of WA pano the other of NA pano) toward the same object point $\mathrm{P}$ must have the same value. One can estimate the difference $\alpha_{\mathrm{y}}=\mathrm{Z}_{\mathrm{WA}}-\mathrm{Z}_{\mathrm{NA}}$ to add to the NA zenithal directions to get their correct values.

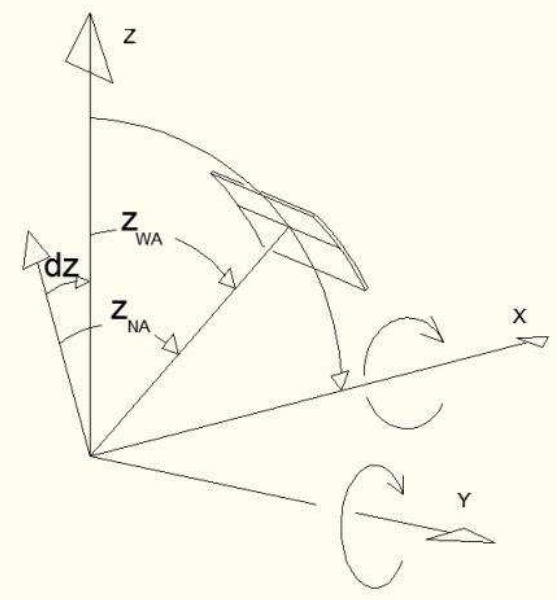

Figure 1: The geometry of Narrow Angle panorama

The described technique has been successfully employed in the two examples here described, that are the survey of the three minarets of the Great Omayyad Mosque in Damascus, Syria and the survey of San Barnaba's spire in the Sagrada Familia in Barcelona, Spain.

\section{THE GREAT MOSQUE OF OMAYYADS IN DAMASCUS, SYRIA}

The Umayyad Mosque of Damascus, Syria, is one of the greatest and most noticeable mosques in the world (figures 1 and 2). The mosque was built on the site of a Christian basilica dedicated to John the Baptist since the time of the 
Roman emperor Constantine. The exterior walls of the mosque are still of roman construction. Inside the courtyard the walls are covered by beautiful mosaics, the largest ever. The center of the courtyard is occupied by the ablution fountain, at the two opposite corners of the temple two minarets, the so-called Jesus minaret on the left (east side) and the Qayit Bay Minaret on the right (west side) (figure 1). In the center of the northern side there is the Bride minaret (figure 2).

\subsection{The Survey}

In August 2010 the survey was carried out using a camera, Canon Eos 450D mounted on the spherical head held by a photographic tripod. The survey was limited to the outdoor. The mosque has three minarets, the minaret of the Bride, the minaret of Jesus, and the minaret of Qayt Bay. Their heights are conspicuous reaching 70 meters above the court pavement. The layout of the panorama network is visible in figure 5. For the photographic takings of the outside of the whole monument some 40 stations have been made, in practice from all the available positions. For the takings of the minarets three types of lenses have been used $28 \mathrm{~mm}, 50 \mathrm{~mm}$, and $200 \mathrm{~mm}$ from the same station points. In the network adjustment we added the constraints for the taking points of different focal lens panorama, to be coincident. We used also the selfcalibration, consisting in the estimation of the camera focal length. In this manner we could estimate correctly the correction angles for the NA panorama, as it is described in 2. Here we present the restitution of the minarets only, although the whole complex of the exterior surfaces of th walls have been plotted. The plotting of the minarets was successful and the accuracy was satisfactory. In figures 6, 7 some views of the minarets are displayed, in particular of the most conspicuous one, the Qayt Bay minaret.

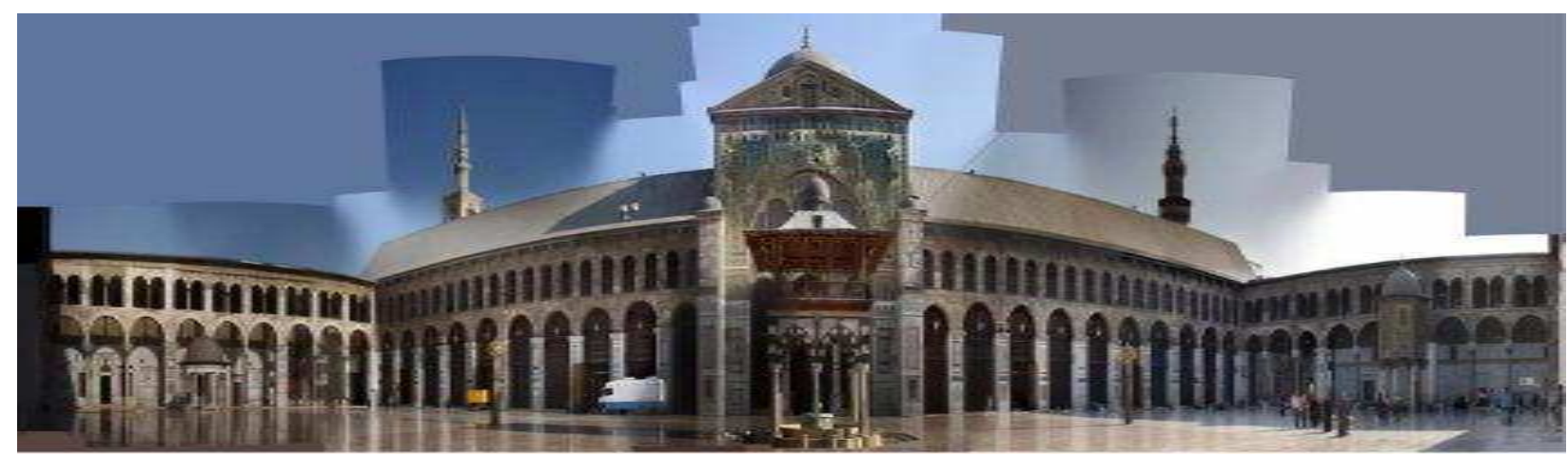

Figure 2: Panorama of the front (southern side) of the mosque. On the center the ablution fountain, on the left the Minaret of Jesus on the right the Qayt Bay minaret.

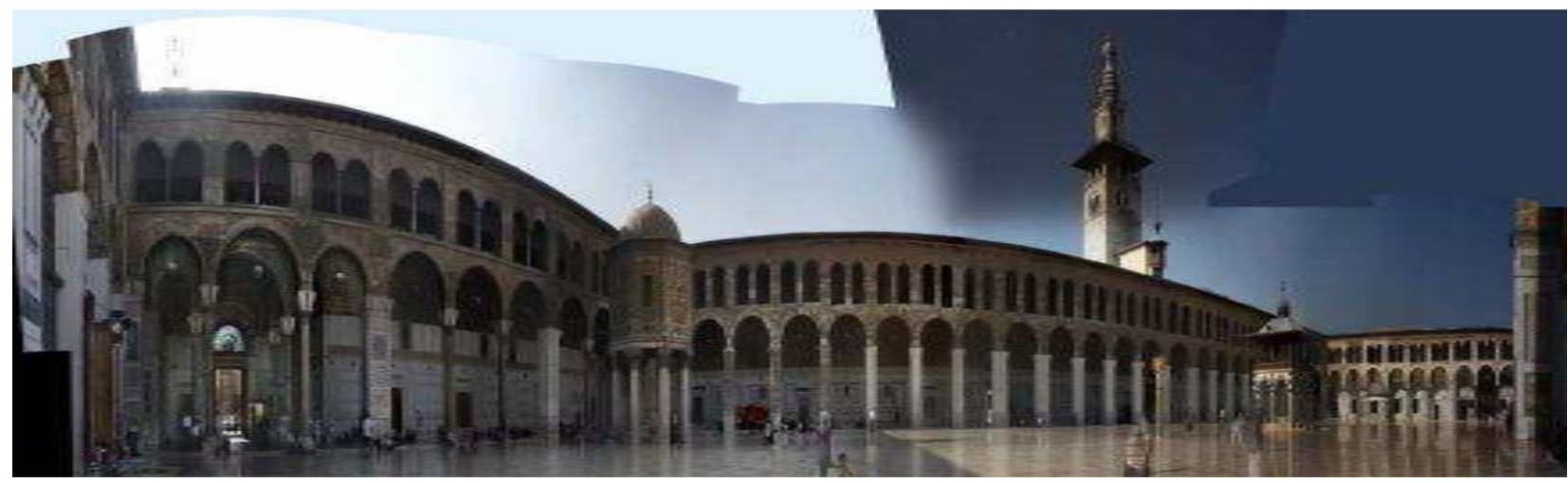

Figure 3: Panorama of the entrance (northern) side of the mosque. The Bride minaret is visible 


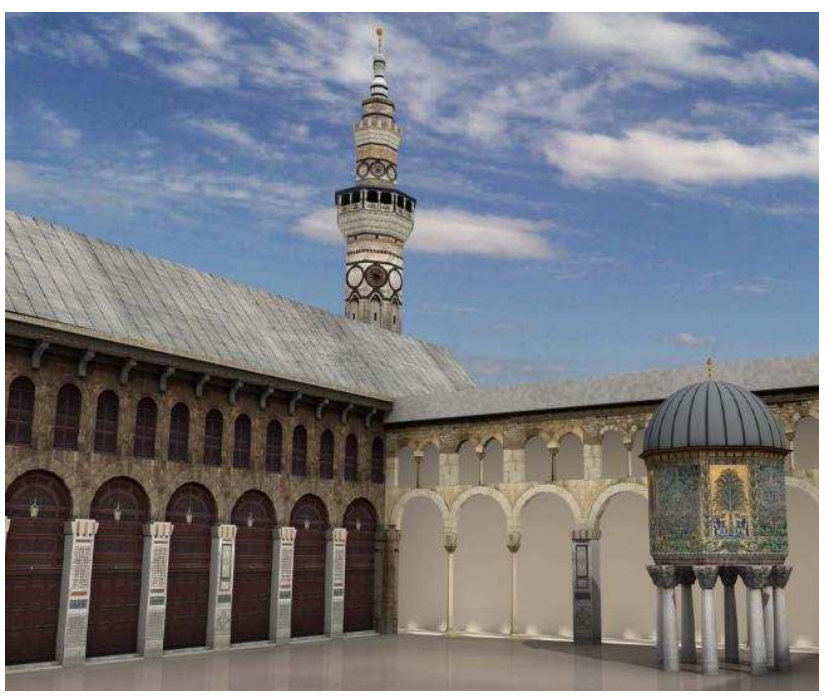

Figure 4: Corner of the courtyard and the Qayt Bay Minaret, rendering

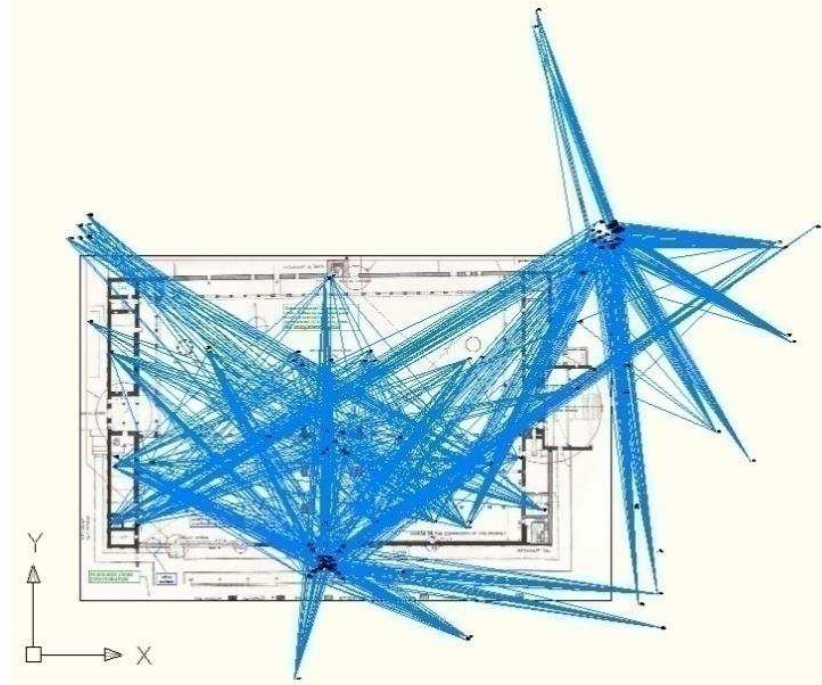

Figure 5: Damascus - Great Mosque, The orientation network of the panorama Survey
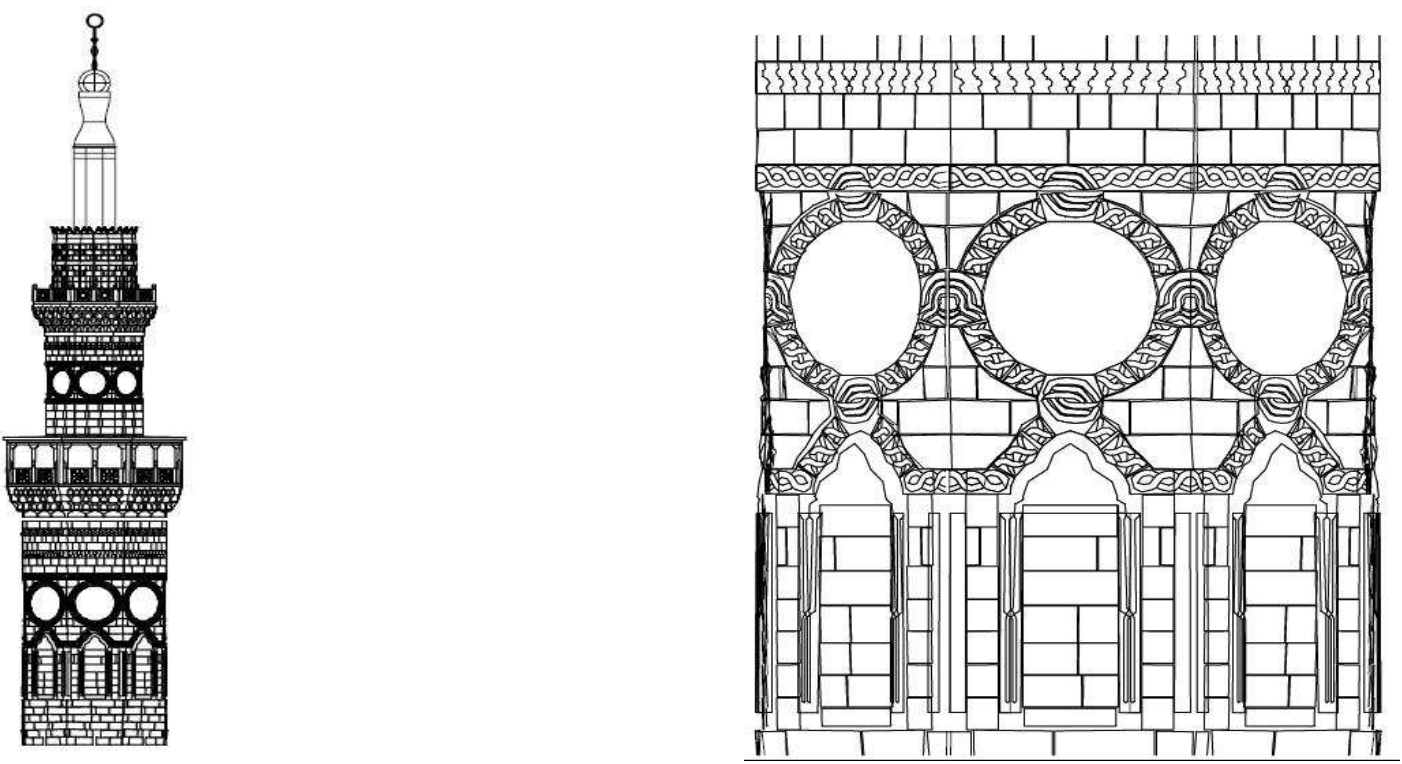

Figures 6, 7: Minaret f Qayt- Bay - western-southern side, the view and some details

\section{THE SAGRADA FAMILIA IN BARCELONE - THE SURVEY OF SAN BARNABA SPIRE BY SPHERICAL PHOTOGRAMMETRY}

The san Barnaba spire was the only one built by the architect A. Gaudi himself, just before his accidental death in 1923. Any of the eight spires placed on the two opposite façades, the Nativity's façade -western side- and the façade of the Passion - east side - is dedicated to a different saint. The top of the spire has an elevation of about 100 meters above the street pavement. Twenty years ago, we made the survey of the spire making use of a camera equipped with $300 \mathrm{~mm}$ focal lens. We oriented the camera with DLT approach (1, Clini, Fangi). We wanted to repeat the experience using the 
spherical photogrammetry. We could make panoramas only from the Marina square, because the opposite side, facing south-west, was not visible any more due to the roof of the church, built in the meantime. So we had to use the original images. We made a combined adjustment orientation, non metric images with DLT approach, and spherical panorama, using the original control network and control points. In addition for any station we made three panoramas, with three different focal length, $50 \mathrm{~mm}, 200 \mathrm{~mm}$, and $500 \mathrm{~mm}$. For the orientation of NA panorama we followed the approach described in 2 .

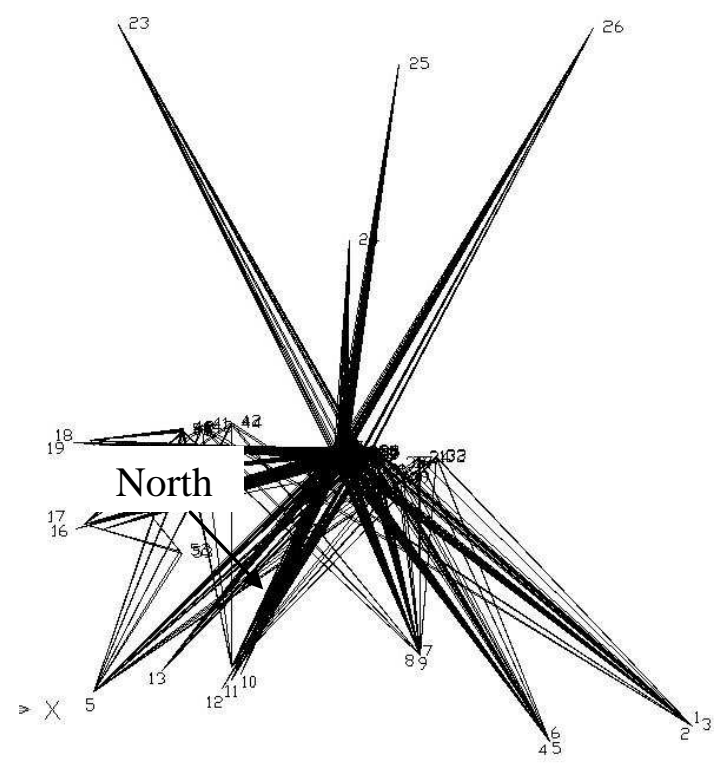

Figure 8: Barcelona - Sagrada Familia, The orientation network - The southern stations are the old ones made in 1990, the 2010 panorama are the northern side. We could make a combined adjustment DLT + pano, putting in the same adjustment block non-metric images and panoramas, using the old control points.

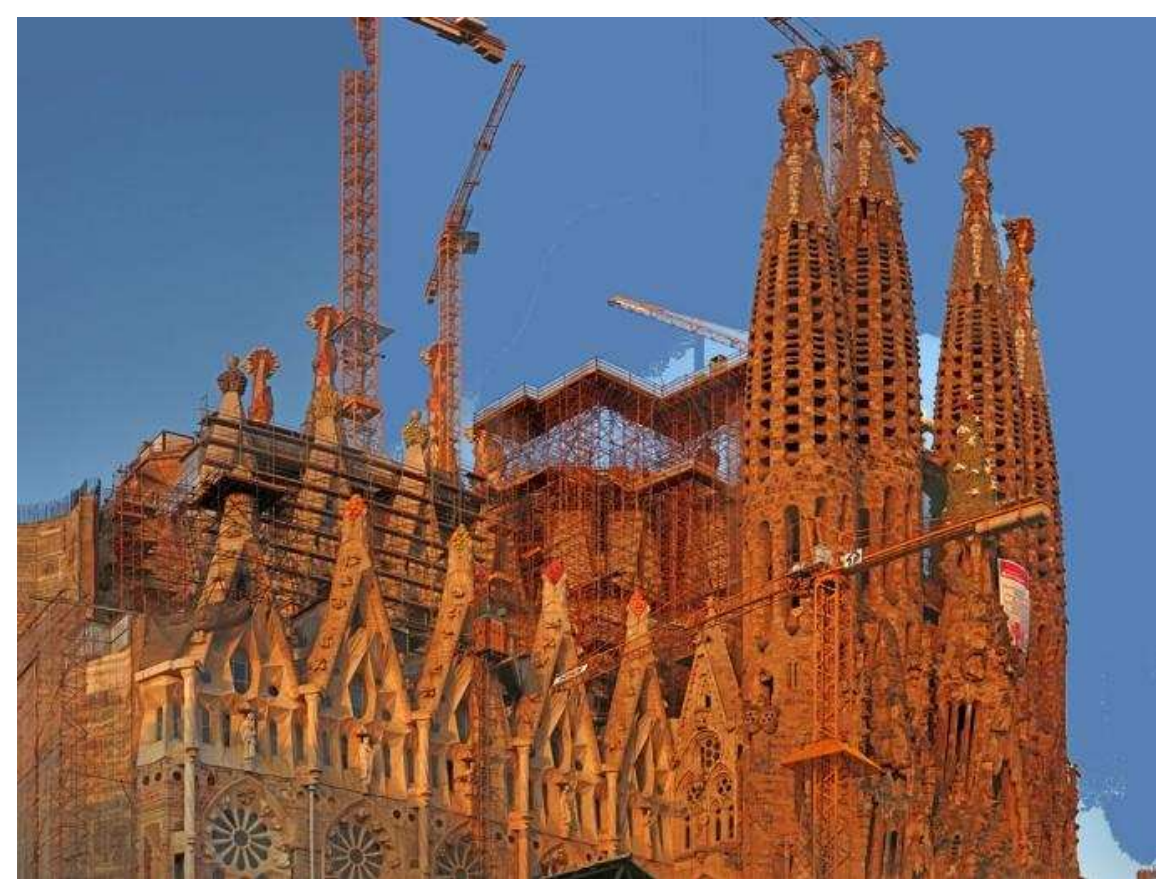

Figure 9: Panorama $50 \mathrm{~mm}$ focal length showing the Nativity Façade - The san Barnaba's spire is the one on the left 


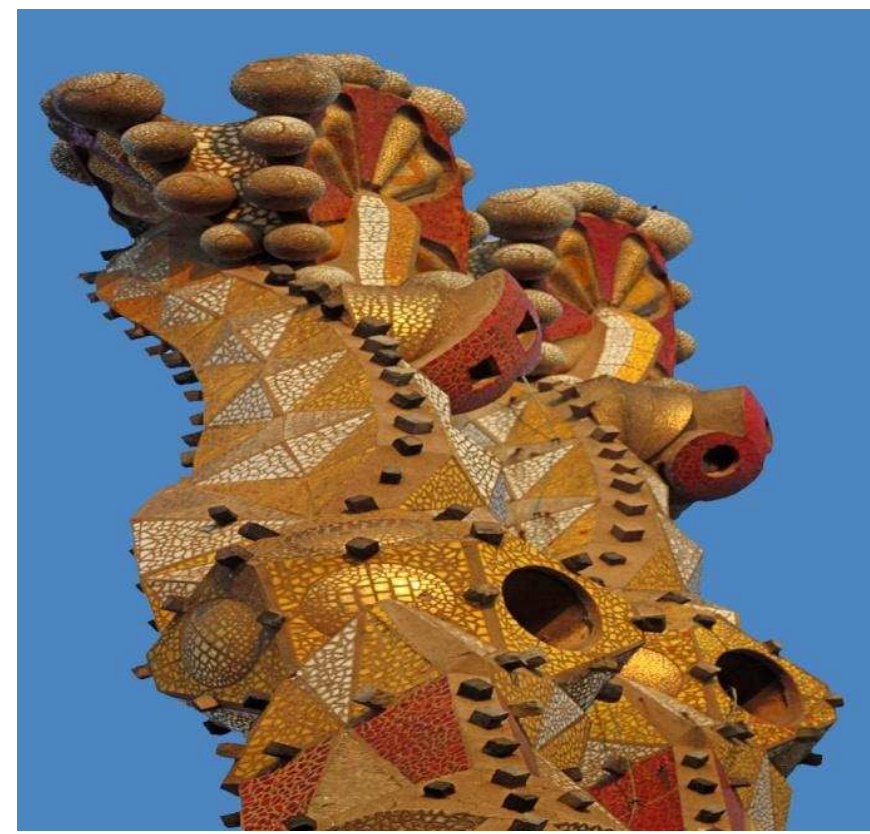

Figure 10: Panorama made with $500 \mathrm{~mm}$ focal length. The $500 \mathrm{~mm}$ panorama complete at $360^{\circ}$ would be of the width of 600.000 pixel. The letter B stands for Barnaba

In figure 9 a panorama made with $50 \mathrm{~mm}$ focal length, and in figure 10 a panorama $500 \mathrm{~mm}$ focal length, the different resolution is evident. In a panorama with large scale, very many details are visible, including all the small pieces covering the spire. The size of the shield is 3 meters, the diameter of the balls range from 80,60 to $50 \mathrm{~cm}$. The top of the spire, covered by glass, shining in the sun, is 17 meters long. It would have been impossible to orient such a panorama without the "help" of WA panorama.

\section{CONCLUSIONS}

A procedure for the appropriate orientation for long range survey has been developed and tested using the algorithms of spherical photogrammetry. The procedure consists in making from the same station point more than one panorama only using different focal lenses. The views made with telephoto lenses must necessarily be restricted to a limited area of the sphere, have good resolution, however, have an unstable geometry and are difficult to orient, while the panoramas made with wide angle lenses have poor resolution, but good geometry. The coupling between the two types of views can combine the advantages and eliminate the weaknesses of both types. This technique is advantageous in the case of surveys of bell towers, minarets and pinnacles, or long-range objects. It has been also presented a case of the combined adjustment of non metric images, oriented with the DLT algorithm, and self-calibrated spherical panoramas.

\section{AKNOWLEDGEMENTS}

The A. wish to thank Domenico Azzarone for the restitution of the San Barbaba Spire.

\section{REFERENCES}

[1] P. Clini , G. Fangi (1991) - Two examples of non-conventional photogrammetric techniques: the nativity's interior facade and the spire of S.Barnaba's bell tower in the Sagrada Familia - Barcelona - Cipa XIV Intern. Symp. Delphi october 1991, 169-182

[2] G.Fangi- Una nuova fotogrammetria architettonica con i panorami sferici multimmagine-Sifet, Symposium Arezzo, 27-29 Giugno 2007, CD 
[3] G.Fangi - The Multi-image spherical Panoramas as a tool for Architectural Survey- XXI International CIPA Symposium, 1-6 October 2007, Atene, ISPRS International Archive - vol XXXVI-5/C53 - ISSN 1682-1750 - CIPA Archives vol. XXI-2007 ISSN 0256-1840 - pg.311-316

[4] G.Fangi (2007) - La Fotogrammetria sferica dei mosaici di scena per il rilievo architettonico - bollettino SIFET n. 32007 pg 23-42

[5] G.Fangi, P.Clini, F.Fiori (2008) - Simple and quick digital technique for the safeguard of Cultural Heritage. The Rustem Pasha mosque in Istanbul - DMACH 4 - 2008 - Digital Media and its Applications in Cultural Heritage 5 - 6 November, 2008, Amman pp 209-217

[6] G.Fangi (2008) - El levantamiento fotogrametrico de Plaza de Armas en Cuzco por medio de los panoramas esfericos - XXX CONVEGNO INTERNAZIONALE DI AMERICANISTICA

Perugia (Italia), 6-12 maggio 2008

[7] E.D'Annibale, G.Fangi (2009) -Interactive modeling by projection of oriented spherical panorama - 3D-Arc'2009, 3D Virtual Reconstruction and Visualization of complex Architectures - Trento 25-29 February 2009- ISPRS ArchivesVol XXXVIII-5/W1 : 1682-1777 su cd

[8] G.Fangi (2009) -Further Developments of the Spherical Photogrammetry for Cultural Heritage - XXII Cipa Symposium, Kyoto, 11-15 October 2009

[9] G.Fangi (2010) - Multi-scale Mult-resolution Spherical Photogrammetry With Long Focal Lenses For Architectural Surveys -ISPRS mid-term symposium NewCastle, June 2010

[10] E.d'Annibale, S.Massa, G.Fangi (2010) - Photomodeling and point clouds from spherical panorama - Nabatean architecture in Petra, Jordan- Workshop Petra 4-8 November 2010

[11] C. Pisa, F. Zeppa, G. Fangi - Spherical Photogrammetry For Cultural Heritage - San Galgano Abbey, Siena, Italy And Roman Theatre, Sabratha, Libya ACM Florence eHeritage 2010 25-10-2010

[12] L.Barazzetti, G.Fangi, F.Remondino, M.Scaioni, (2010) Automation in Multi-Image Spherical Photogrammetry for 3D Architectural Reconstructions - The 11th International Symposium on Virtual Reality, Archaeology and Cultural Heritage VAST (2010) A. Artusi, M. Joly-Parvex, G. Lucet, A. Ribes, and D. Pitzalis (Editors)

[13] R. Szeliski and H. Shum. (1997) Creating full view panoramic image mosaics and environment maps. In Proc. of SIGGRAPH, pages 251-258

[14] www.cipa.icomos.org/objectives

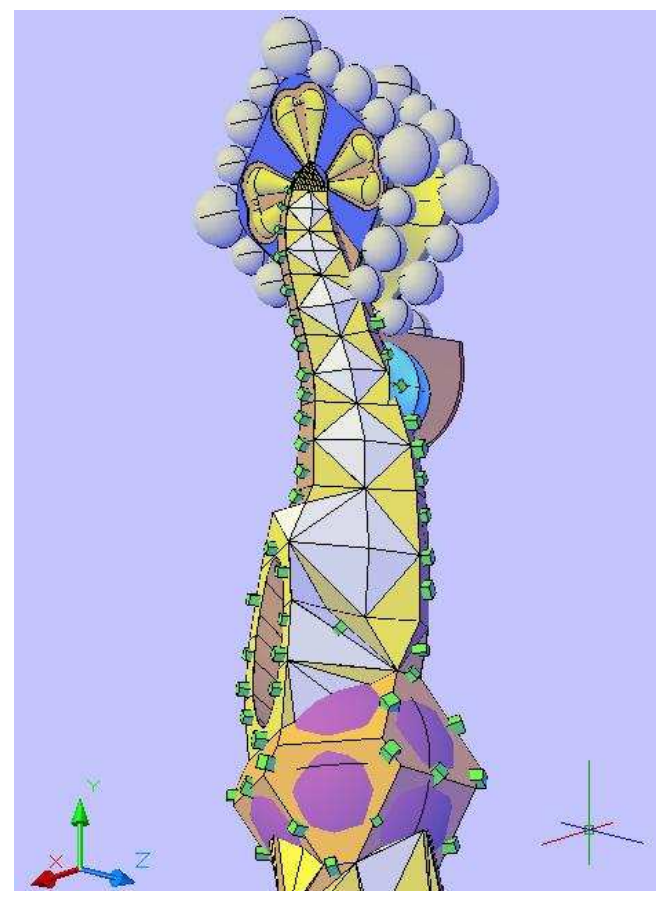

Figure 11: The 3D model of the spire (plotting by D.Azzarone) 


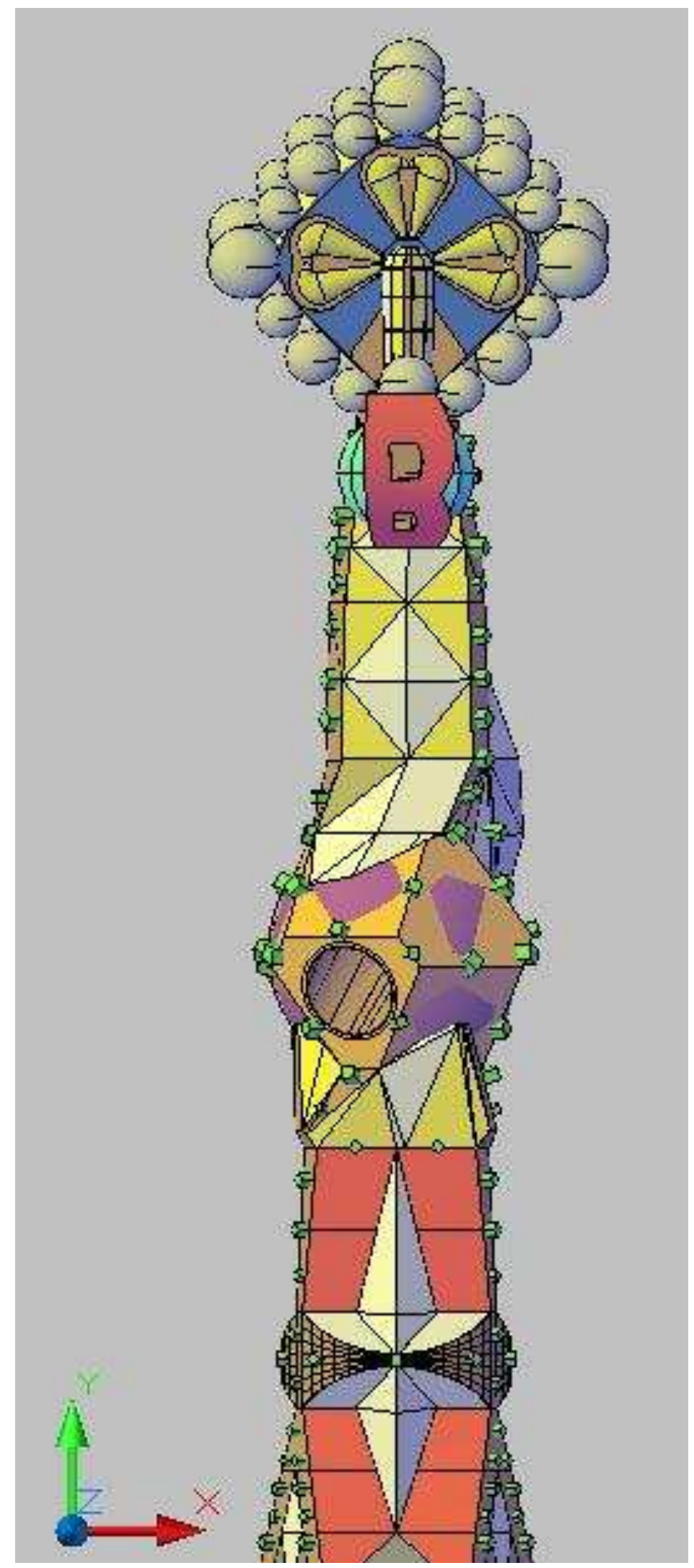

Figure 12: The 3D model of the spire (plotting by D.Azzarone) 


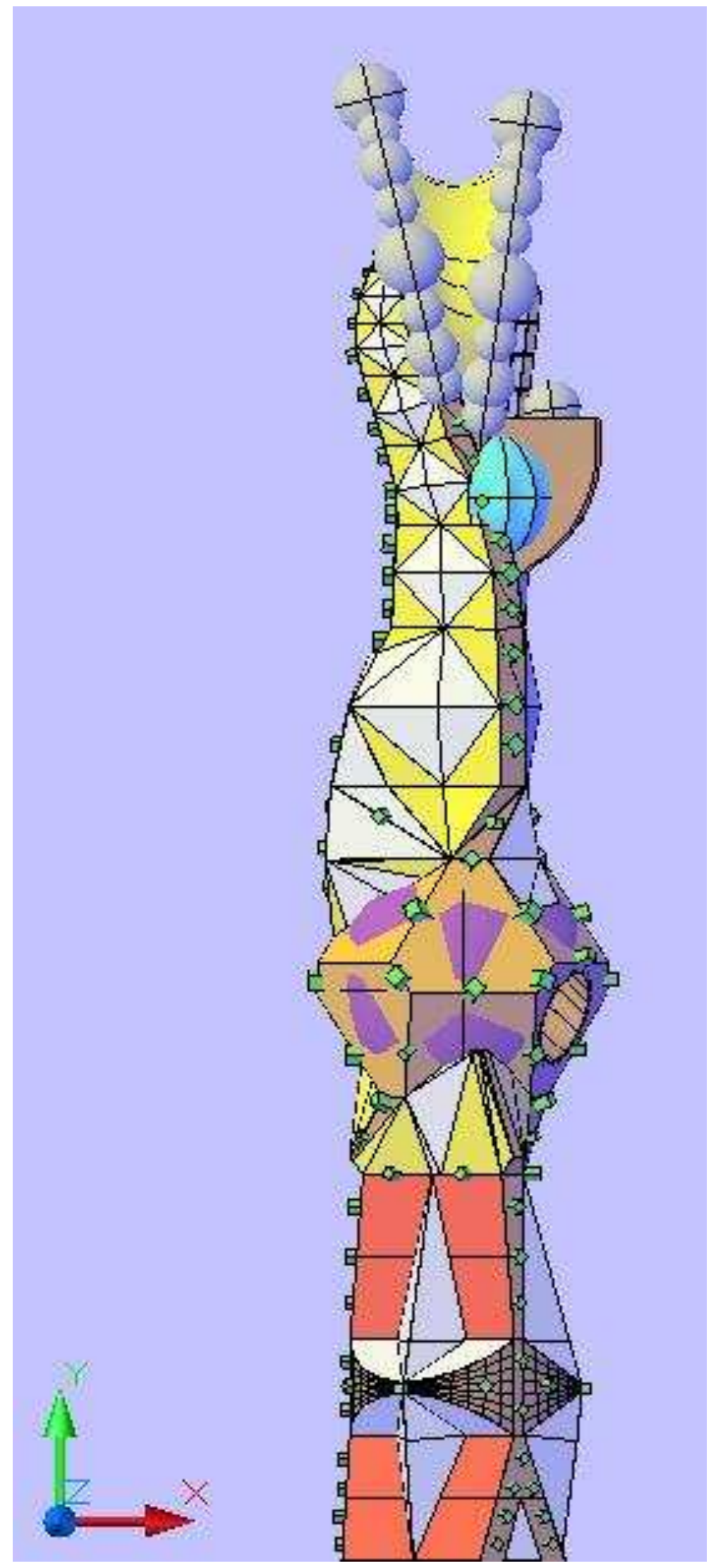

Figure 13: The 3D model of the spire (plotting by D.Azzarone) 